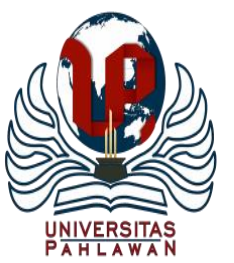

Jurnal Abdidas Volume 1 Nomor 4 Tahun 2020 Halaman 277 - 283

JURNAL ABDIDAS

Community Development Service on Educational and Health Sciences

http://abdidas.org/index.php/abdidas

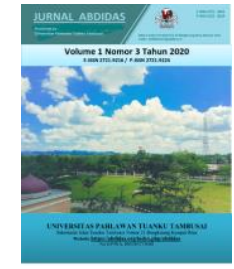

\title{
Pelatihan Strategi Pemasaran, Bisnis Dan Keuangan Produk Rumahan Masyarakat Desa Durian Kec. Pantai Labu
}

\author{
Masta Sembiring ${ }^{1}$, Eko Febri Syahputra Siregar ${ }^{2}$ \\ Universitas Muhammadiyah Sumatera Utara ${ }^{1,2}$ \\ E-mail: mastasembiring@umsu.ac.id ${ }^{1}$ ekofebrisyahputra@umsu.ac.id ${ }^{2}$
}

\begin{abstract}
Abstrak
Pengabdian kepada masyarakat ini bertujuan untuk peningkatan kesejahteraan masyarakat melalui peningkatan sumber daya manusia agar lebih memiliki daya saing di masyarakat. Manfaat secara umum pengambilan ini bertujuan adalah untuk memberikan pelatihan kepada masyarakat Desa Durian, Kecamatan Pantai Labu, Kabupaten Deli Serdang. Pengabdian ini bermanfaat untuk kelangsungan usaha dalam dunia bisnis yang berkesinambungan agar taraf kehidupan masyarakat dan kesejahteraan masyarakat teratasi. Metode pengabdian kolaborasi dengan ceramah, pelatihan dan diskusi. Masa waktu pelatihan ini adalah 6 bulan. Dari pengabdian ini, memperoleh hasil adalah mitra sudah mampu dan paham mempromosikan dan mengemas hasil produksi secara menarik sehingga produk yang ditawarkan dapat memiliki nilai jual yang lebih tinggi dan dapat terjual lebih banyak lagi.
\end{abstract}

Kata kunci: pengabdian kepada masyarakat, kolaborasi dosen mahasiswa

\begin{abstract}
Community Service is aimed at improving the welfare of the community through increasing human resources to be more competitive in the community. The general benefit of this service is to provide training to the community of Durian Village, Labu Beach District, Deli Serdang District. This dedication is beneficial for business continuity in a sustainable business world so that the standard of living of the community and the welfare of the community are overcome. Collaborative service delivery methods with lectures, training and discussions. The training period is 6 months. From this service, the results are that partners are able and understand to promote and package their products in an attractive manner so that the products offered can have a higher selling value and can sell more.
\end{abstract}

Keywords: community service, collaboration of student lecturer

Copyright (c) 2020 Masta Sembiring, Eko Febri Syahputra Siregar

$\triangle$ Corresponding author :

Address : Universitas Muhammadiyah Sumatera Utara

ISSN 2721-9224 (Media Cetak)

Email : mastasembiring@umsu.ac.id

ISSN 2721- 9216 (Media Online)

Phone :

DOI : https://doi.org/10.31004/abdidas.v1i4.53 


\section{PENDAHULUAN}

Desa Durian merupakan salah satu desa yang ada di Kecamatan Pantai Labu, Kabupaten Deli Serdang, Provinsi Sumatera Utara. Kecamatan Pantai Labu adalah sebuah kecamatan yang berada di pesisir timur Kabupaten Deli Serdang, sehingga kecamatan ini mempunyai wilayah laut dan sebagian masyarakat di Kecamatan Pantai Labu hidup dari hasil laut, bermata pencaharian sebagai Petani, Buruh dan Profesi lainnya. Walaupun Desa Durian berada di Kecamatan Pantai Labu, desa ini tidak langsung berbatasan dengan laut. Di desa durian sangat banyak produk-produk rumahan yang dihasilkan dan dipasarkan, namun karena kurangnya pemahaman terhadap pemasaran dan keuangan maka masyarakat sekitar tidak mampu mengembangkan usaha kecil itu menjadi usaha yang lumayan besar. Dalam jurnal Annysa Endrastuti dalam judul "Pelatihan Pemasaran, Pemberdayaan Toko Online, dan Pengenalan MCommerce pada Produk Unggulan Jagung Tortila di Kecamatan Trucuk Kabupaten Bojonegoro" mengatakan bahwa di era MEA, para pelaku UMKM di Indonesia dituntut untuk semakin inovatif dalam mendesain dan memasarkan produk mereka. Kendala yang selama ini mereka hadapi, selain modal, teknologi rendah, dan kurangnya kualitas dan kuantitas SDM adalah proses pemasaran yang belum menyeluruh. Dengan demikian bisa kita lihat salah satunya adalah kegiatan memproduksi gula merah. Usaha Pak Dedi, yaitu gula merah Pak Dedi. Kegiatan yang dilakukan pada usaha gula aren berada di Dusun III Desa Durian yang dikelola oleh Bapak Dedi.
Usaha yang dilakukan oleh Bapak Dedi tersebut sudah dilakukan secara turun temurun, hanya saja Bapak mulai mendirikan usaha tersebut sendiri sudah 15 tahun. Dengan adanya kegiatan pengabdian dari Universitas Muhammdiyah Sumatera Utara, ini maka diharapkan masyarakat yang memiliki usaha rumahan pada desa durian akan terbantu dalam pemasaran dan pembukuan keuangannya. Jika biasanya pembukuan keuangan perusahaan besar diserahkan pada seorang akuntan profesional. Berikut ini jenis-jenis catatan yang rekomendasikan dalam cara pembukuan keuangan usaha kecil bagi yang baru saja memulai usaha: memuat buku catatan pengeluaran, menyiapkan buku catatan pemasukan, membuat buku kas utama, mempersiapkan secara khusus buku stok barang, membuat buku inventaris barang mempersiapkan buku laba rugi.

Gula merah yang terbuat dari aren, berbeda dengan gula merah biasa seperti gula Jawa dan lainya. Banyak orang tidak bisa membedakan jenis jenis gula merah tersebut. Gula aren memiliki warna yang cenderung lebih terang jika dibandingkan dengan gula Jawa, warna gula aren yakni kuning kemerahan. Sedangkan gula Jawa, mempunyai warna cokelat yang agak gelap, sesekali gula Jawa ini juga menampakkan warna sedikit kemerahan. Gula merah Pak Dedi biasa dipasarkan di sekitaran Desa Durian, Baku Sentang dan Beringin. Proses pembuatan gula aren memakan waktu yang sangat lama, proses pengolahan dari pukul 09.00-14.00 WIB. Gula aren dibuat dengan campuran aren, gula pasir, dan juga sedikit minyak makan. Menurut Dedi, cita 
rasa gula merah yang dihasilkan pohon aren lebih memiliki cita rasa yang lebih khas dan nikmat.

Namun dikarenakan pemasaran yang kurang penjualan gula merah Pak Dedi hanya sampai Desa Durian saja. Di era teknologi yang canggih ini, seharusnya pemasaran dan penjualannya bisa maksimal. Namun dikarenakan kurangnya pemahaman terkait pemasaran berbasis teknologi yaitu pemasaran online maka Pak Dedi hanya menjual pada beberapa warung terdekat. Dengan adanya pengabdian masyarakat yang diadakan Universitas Muhammadiyah Sumatera Utara, sangat membantu para pedagang kecil di Desa Durian Pantai Labu, khususnya produk gula merah Pak Dedi. Pak Dedi diajarkan bagaimana memasarkan daganganya melalui media sosial. Seperti yang dikatakan Roni Saeful Hidayat dalam “Analisis Saluran Pemasaran Gula Aren pada Desa Capar Kabupaten Brebes", para pengusaha kecil seperi Pak Dedi hanya fokus pada mendapatkan uang tunai dan mencukupi keluarganya saja, tidak terpikir untuk memperluas target pasar dengan melakukan strategi pemasaran.

a. Pengertian Pemasaran

Menurut Kotler dan Keller (2009:9) pemasaran adalah suatu proses sosial dan manajerial yang didalamnya individual dan kelompok mendapatkan apa yang mereka butuhkan dan inginkan dengan menciptakan, menawarkan dan menukarkan produk dan jasa yang bernilai dengan pihak lain".

b. Strategi Pemasaran

Strategi pemasaran pada dasarnya adalah suatu rencana yang menyeluruh serta terpadu dan menyatu di bidang pemasaran barang dan jasa. Dengan perkataan lain, strategi pemasaran itu adalah serangkaian tujuan dan sasaran kebijakan, serta aturan yang memberi arah kepada usaha-usaha pemasaran barang dan jasa. Strategi pemasaran adalah wujud rencana yang terarah di bidang pemasaran, untuk memperoleh suatu hasil yang optimal.

Strategi pemasaran menurut Kotler dan Keller (2000:93) mengatakan bahwa "Strategi pemasaran adalah logika pemasaran dan berdasarkan itu unit bisnis diharapkan untuk mencapai sasaran-sasaran pemasaran, strategi pemasaran terdiri dari pengambilan keputusan tentang biaya pemasaran dari perusahaan".

c. Faktor-faktor Pemasaran

Menurut Marius P Angipora (2000) ada 4 faktor yang mempengaruhi keputusan pembelian dimana 4 faktor tersebut akan dijadikan indikator, karena pada dasarnya konsumen tidak sembarangan dalam membuat keputusan pembelian. 4 faktor tersebut yaitu:

1. Faktor Budaya

a) Budaya, perilaku pembeli seseorang sangat dipengaruhi oleh budaya, karena merupakan faktor penentu yang paling mendasar keinginan dan perilaku seseorang

b) Subbudaya, dimana dalam subbudaya yang merupakan suatu budaya bagi setiap kelompok dan tiap budaya memiliki kelompok subbudaya lebih kecil yang memberikan sosialisasi dan identifikasi yang lebih spesifik bagi para anggotanya. 
c) Kelas sosial, bagian yang relatif homogen dan selalu ada di dalam suatu masyarakat yang tersusun secara hirarki dan yang para anggotanya memiliki nilai-nilai kepentingan dan perilaku yang sama.

\section{Faktor Sosial}

a) Kelompok

Kelompok yang mempengaruhi langsung (tahap muka) atau tidak langsung terhadap sikap dan perilaku orang tersebut.

b) Keluarga

Keluarga adalah peran lain tidak boleh diabaikan dalam menentukan perilaku pembeli untuk membeli setiap barang atau jasa yang dibutuhkan.

c) Peran dan Status

Seperti yang telah dijelaskan dalam faktor-faktor yang mempengaruhi perilaku konsumen dimana salah satunya dipengaruhi oleh faktor sosial. Oleh karena itu posisi seseorang dalam setiap kelompok dapat ditentukan dari segi peran dan sosial.

\section{Faktor Pribadi}

a) Usia dan Tahap Siklus Hidup

Membeli juga dibentuk oleh siklus hidup keluarga mengenai tahap-tahap yang mungkin dilalui keluarga sesuai kedewasaannya. Dari usia muda, usia pertengahan, dan usia tua.

b) Pekerjaan

Pekerjaan seseorang mempengaruhi barang dan jasa yang mereka beli. c) Situasi Ekonomi

Situasi ekonomi mempengaruhi pilihan produk, dimana pemasaran produk yang peka terhadap pendapatan mengamati kecenderungan dalam pendapatan pribadi, tabungan, dan tingkat minat.

d) Gaya Hidup

Gaya hidup adalah pola kehidupan seseorang yang diwujudkan dalam psikografisnya. Gaya hidup yang dimaksud adalah mengenai aktivitas (pekerjaan, hobi, berbelanja, olahraga, dan kegiatan sosial).

e) Kepribadian dan Konsep Diri

Kepribadian mengacu pada karakteristik psikologi unik seseorang yang menyebabkan respon yang relatif konsisten dan bertahan lama terhadap lingkungan orang itu sendiri.

\section{Faktor Psikologis}

a) Motivasi

Motivasi adalah kebutuhan dengan tekanan kuat yang mendorong seseorang untuk mencari kepuasan atas kebutuhan tersebut.

b) Persepsi

Persepsi adalah proses dimana orang memilih, mengatur dan menginterpretasikan informasi untuk membentuk gambaran dunia yang berarti.

c) Pembelajaran

Perubahan dalam perilaku seseorang yang timbul dari pengalaman.

d) Keyakinan dan Sikap 
Pemikiran deskriptif yang dimiliki seseorang mengenai sesuatu. Sikap adalah evaluasi, perasaan, dan tendensi yang relatif konsisten dari seseorang terhadap sebuah objek atau ide

\section{METODE}

Strategi pemasaran yang diperkenalkan kepada masyarakat Desa Durian Kecamatan Pantai Labu yakni :

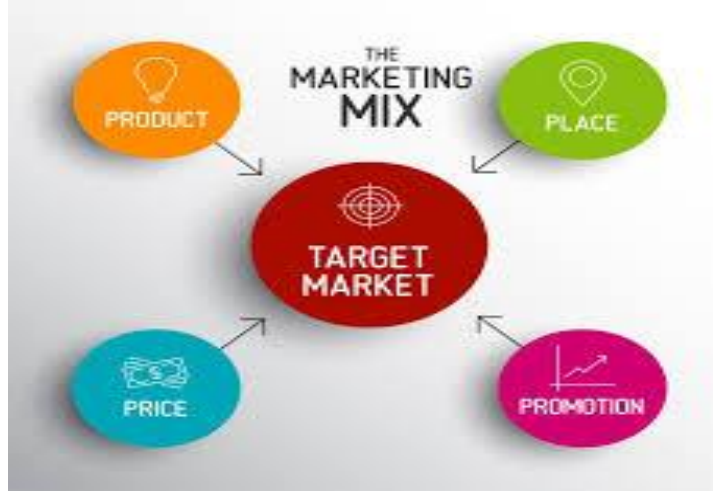

Gambar 1. Marketing Mix

Dari gambar diatas merupakan gambar metode marketing mix. Kaitan antara produk, price, place dan promotion. Keempat komponen tersebut harus diperhatikan untuk mencapai target pasar. Masyarakat pedagang kecil diajarkan dan diarahkan untuk memahami marketing mix. Dimana kaitan antara produk, price, place dan promotion adalah sangat kuat untuk melakukan target pasar yang tepat.

Dalam memberikan solusi terhadap masalah produksi, pemasaran dan keuangan pada usaha gula aren yang berada pada desa durian tersebut penulis memiliki tahapan dalam memberi pelatihan kepada masyarakat desa.
Masyarakat desa khususnya yang memiliki usaha rumahan seperti gula merah dan yang lainya diajak berkumpul di suatu tempat yakni Balai Desa. Kemudian dosen dan mahasiswa menyiapkan materi yang akan disampaikan kepada masyarakat penghasil produk. Dalam penyampaian materi memasarkan produk agar lebih dikenal masyarakat selain masyarakat Desa Durian baik offline ataupun online. Kemudian warga diajak praktik langsung dalam mempromosikan produk secara online. Selanjutnya memberi pemahaman dan pengetahuan bagaimana perhitungan penghasilan per hari, biaya dan laba per bulannya. Dan terakhir memberikan sesi tanya jawab tentang apa saja informasi yang masyarakat desa butuhkan Jenis metode pengabdian ini adalah pendidikan masyarakat, konsultasi, dan ceramah. Teknik pengumpulan data pengabdian ini adalah teknik dokumentasi. Teknik analisis pengabdian ini dengan cara langsung survei kelapangan dan menganalisa kegiatan sebelum dilakukannya pelatihan ini. Pelatihan ini dilakukan pada 14 Agustus 2019 selama 3 jam, yakni sore hari.

\section{HASIL DAN PEMBAHASAN}

Tahapan dalam pelatihan adalah, pertama adalah pelatihan mengenai sasaran produk usaha, kemudian bagaimana pengemasan produk dan pembukuan masing-masing pelaku usaha. Pada tahap akhir dilakukan monitoring oleh tim Penelitian dan Pengabdian Kepada Masyarakat (P3M).

Peserta pengabdian adalah bapak-bapak dan ibu-ibu serta muda-mudi yang memiliki usaha dan terlibat dalam paguyuban di Desa Durian. Peserta 
sebanyak 30 orang. Lama pelatihan dilaksanakan selama satu hari, kegiatan monitoring dan pendampingan dilaksanakan selama 3 bulan. Dalam jangka waktu tertentu dilaksanakanlah evaluasi secara berkala terhadap kemajuan produk yang ada di masyarakat. Tahapan selanjutnya atau tindak lanjut berupa penyuluhan dan kerjasama lain ke arah yang lebih akademis. Materi pelatihan berupa cara-cara meningkatkan taraf hidup dan kesejahteraan masyarakat melalui model pemecahan masalah dengan cara memberikan strategi pemasaran produk yang sesuai dengan kebutuhan dan keinginan pasar.

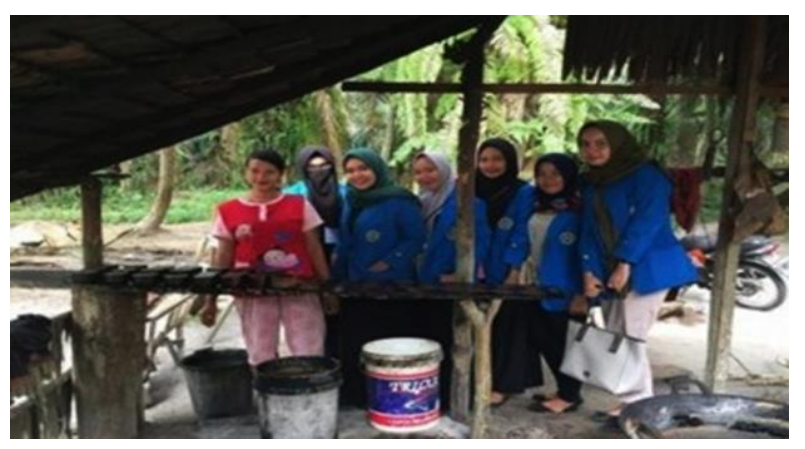

Gambar 2. Kegiatan Mahasiswa Dengan Warga dalam Membuat Gula Merah

Dalam kurun waktu 30 hari kami melihat adanya kemajuan dalam bidang pemasaran khususnya pedagang kecil pada Desa Durian, mereka mengakui produksi dan penjualan mereka bertambah sedikit demi sedikit. Dan tidak sedikit orderan yang datang dari media sosial. Pembukuan mereka pun sudah mulai mencoba merapikan sesuai yang diajarkan. Walaupun masih periode perbulan.

Peserta dipandu agar produk yang dihasilkan mendapatkan legalitas usaha dan bagaimana prosedur dalam mendaftarkan izin usaha. Berikut foto kegiatan yang dilakukan pada Desa Durian Kecamatan Pantai Labu.

\section{SIMPULAN}

Kegiatan KKN (Kuliah Kerja Nyata) yang kami memiliki manfaat bagi warga Desa Durian dalam memperbanyak pasar dan membatu masyarakat sekitar untuk memahami lebih dalam tentang target pasar dan pembukuan keuangan.

\section{DAFTAR PUSTAKA}

Aliudin, Sariyoga, S., \& Anggraeni, D. (2011). Efesiensi dan Pendapatan Usaha Gula Aren Cetak ( Kasus pada Perajin Gula Aren Cetak di Desa Cimenga , Kecamatan Cijaku , Kabupaten Lebak , Provinsi Banten ) Efficiency and Income of Palm Sugar Small Business : A Case Study of Palm Sugar Small Business in. Jurnal Agro Ekonomi, 29(1), 73-85.

Angipora, M. (2002). Dasar-dasar Pemasaran Edisi Kedua. In Raja Grafindo Persada. Jakarta.

Dharmesta, \& Irawan. (1999). Manajemen Pemasaran Modern. Edisi 7. Liberty.Yogyakarta

Endriastuti, A., \& Permatasari, M. P. (2018). PELATIHAN PEMASARAN, PEMBERDAYAAN TOKO ONLINE, DAN PENGENALAN m-commerce PADA PRODUK UNGGULAN JAGUNG TORTILADI KECAMATAN TRUCUK KABUPATEN BOJONEGORO. Martabe: Jurnal Pengabdian Kepada Masyarakat, 1(2), 56. https://doi.org/10.31604/jpm.v1i2.56-66

Kotler, P., \& Keller, K. (2000). Manajemen Pemasaran. Erlangga. Jakarta

Kotler, \& Keller. (2009). Manajemen Pemasaran (12 jilid 1). Jakarta. PT Indeks Kelompok Gramedia. 
283 Pelatihan Strategi Pemasaran, Bisnis dan Keuangan Produk Rumahan Masyarakat Desa Durian Kec. Pantai Labu-Masta Sembiring, Eko Febri Syahputra Siregar

DOI : https://doi.org/10.31004/abdidas.v1i4.53

Saeful, R., Rusman, Y., \& Ramdan, M. (2016). ANALISIS SALURAN PEMASARAN GULA AREN (ARENGA PINNATA) (Studi Kasus di Desa Capar Kecamatan Salem Kabupaten Brebes). Jurnal Ilmiah Mahasiswa AGROINFO GALUH, 2(2), 117124.

W, A. K. (2005). ANALISIS FINANSIAL PENGOLAHAN NIRA AREN (Arenga Pinnata) MENJADI PRODUK NATA PINNATA. Jurnal Penelitian Sosial Dan Ekonomi Kehutanan, 2(1), 17-26. 